Proc. of JSCE,

No. 190, June, 1971

\title{
THE INITIAL CRACKING MOMENTS OF THE BRACKETED PARTS OF CONCRETE BEAMS
}

\author{
Wen-Hsiung Chen*
}

\section{SYNOPSIS}

The beams with brackets at the ends, have the tendency to crack from the reentrent corners of the bracketed parts, the strength of this cracking of reinforced and prestressed concrete beams is investigated.

An equation is presented for predicting the initial cracking moments, the calculated results are checked by the results of experiments which are tested under both moving load and two points load. To simplify the design work, design charts are also presented.

\section{INTRODUCTION}

The beams with brackets at the ends are often used as structural members not only in bridges but also in building frames. The typical example of such beams are the suspended beams of the cantilever bridges. Owing to the abrupt change in the depth of the cross section at the brackets, this type of beams have the tendency to cracking from the reentrent corners of the bracketed parts ${ }^{1)}$. For convenience, these cracks are termed "corner crack". This corner cracks are formed at approximately 50 $\%$ of design load on reinforced concrete beams ${ }^{5}$ ) and approximately $60 \%$ of design load on prestressed concrete beams ${ }^{2)}$ respectively.

The causes of these corner cracks may be considered to be the great increase of shearing stress owing to the great decrease of the beam depth, and sometimes it may occur by the tensile stress due to the nonuniform drying shrinkage, nonuniform temperature distribution during the hardening of concrete, eccentric loading or torsional loading, inability of end rotation at supports and horizontal forces

\footnotetext{
* Graduate student, Graduate Division of Science and Engineering, Waseda University, M. Eng.
}

introduced by the imperfect mechanism of expansion bearings.

There are seveal papers which deal with the bracketed parts of concrete beams. S. Kamiyama ${ }^{7}$ reported the investigation of the strain distribution of the bracketed parts of concrete beams and presented an equation for calculation of shearing stress and the method of reinforcement of this parts. S. Okamoto and $T$. Ishiwata ${ }^{8}$ reported their experimental study on the stress distribution of the reinforced concrete beams, S. Onishi, M. Manabe, and M. Hisamatsu ${ }^{10}$ ) reported the experimental study of prestressed concrete beams. M. Fujii ${ }^{11}$ reported the analytical result of bracketed parts by the finite element method. Y. Nojiri and H. Akiyama ${ }^{12)}$ reported the study on the stresses of bracketed parts by the photoelastic test. All of these papers present excellent data.

The occurence of corner cracks may result in excessive deflections, corrosion of reinforcements, and other critical situation. An investigation of corner cracking strength is then an important problem. The purpose of this paper is to deal with the initial corner cracking moment from the standpoint of diagonal tension, and furthmore, to make the charts of the initial corner cracking moments for practical use.

\section{TEST SPECIMENS}

The data of nine series of seventeen specimens are adopted for comparison with the theoritical values which are calculated by the equation discussed in the following chapters. The specimens identified by the letter $\mathrm{RC}$ are reinforced without prestressing, the specimens identified by the letter PC are reinforced with prestressing, the letter $T$ denotes tee section specimens, the letter $B$ and $N$ denote the specimens which were tested by the two points load, the letter $A$ denotes the specimens which were 


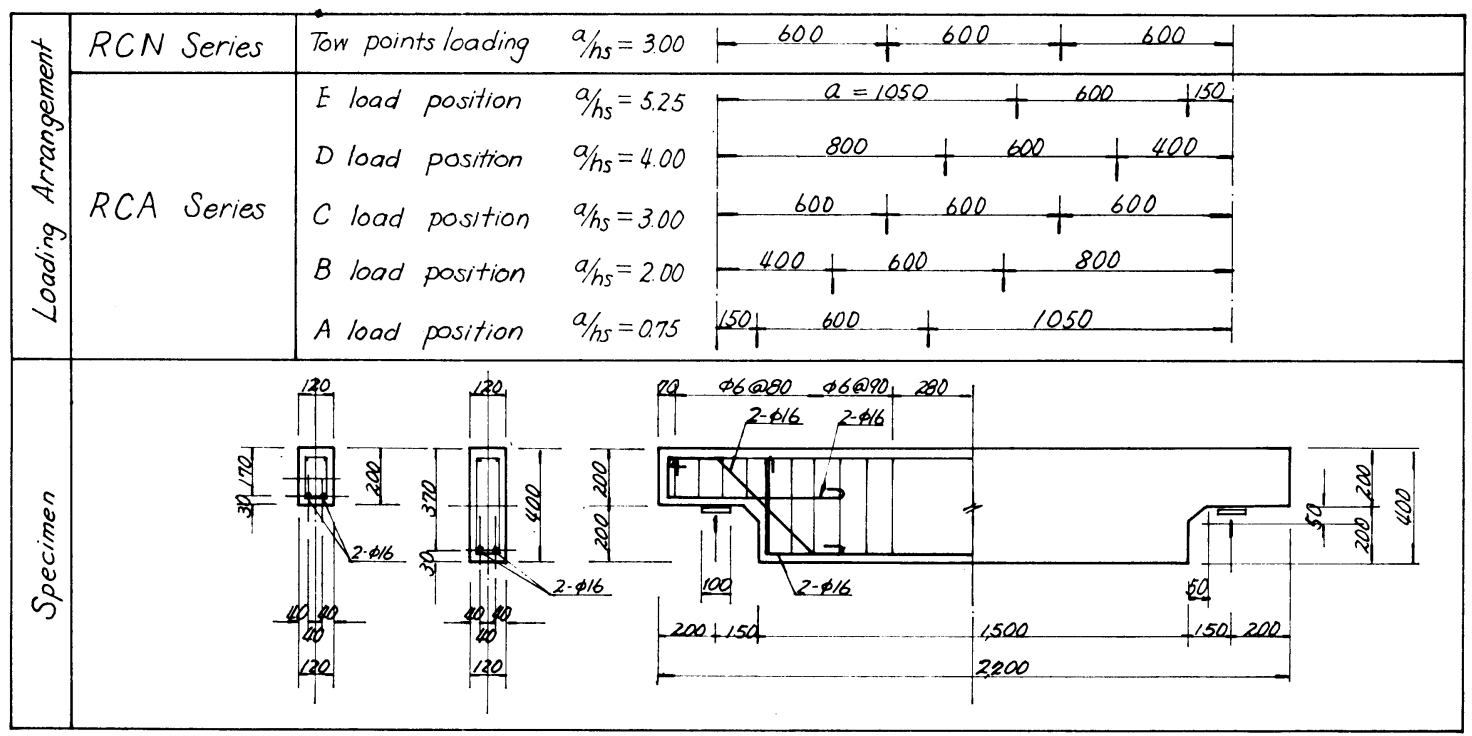

Fig. 1 Specimens and loading arrangement of reinforced concrete rectangular beams

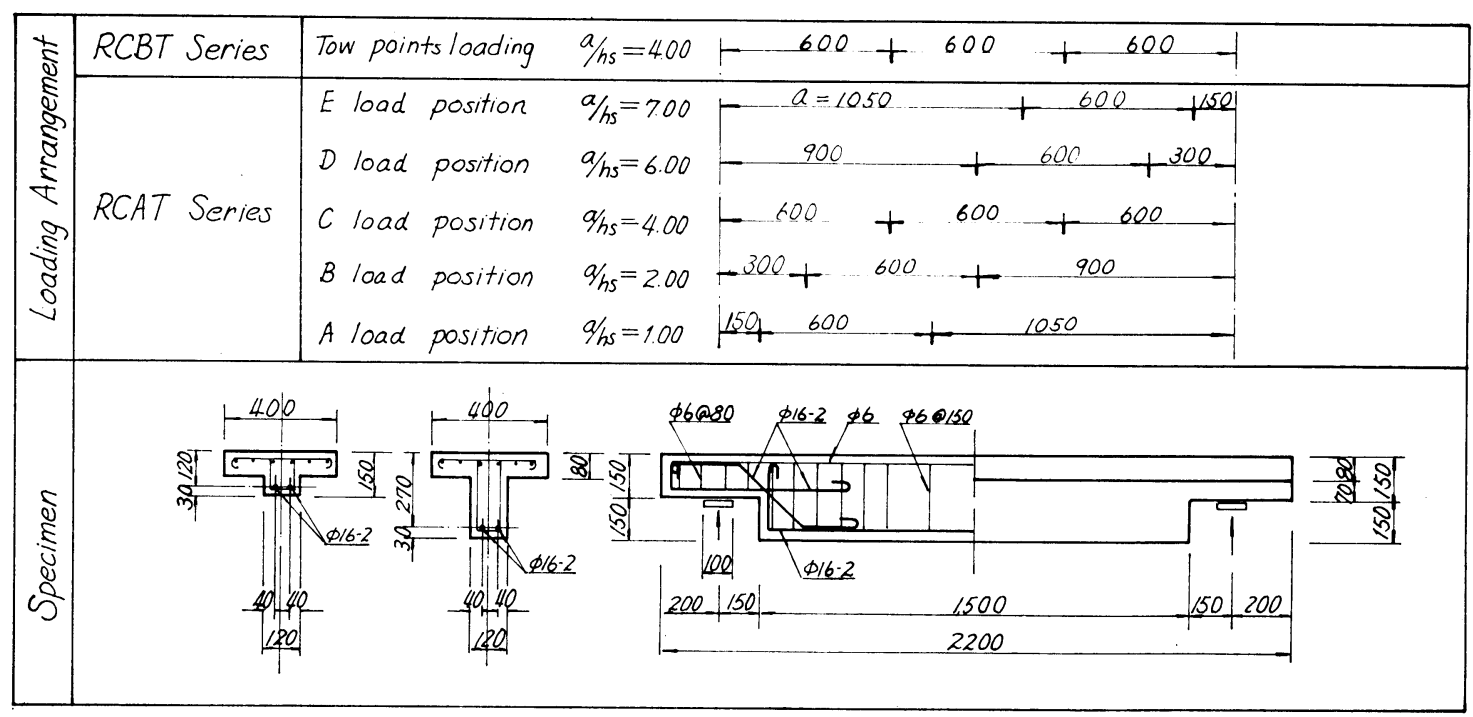

Fig. 2 Specimens and loading arrangement of reinforced concrete tee beams

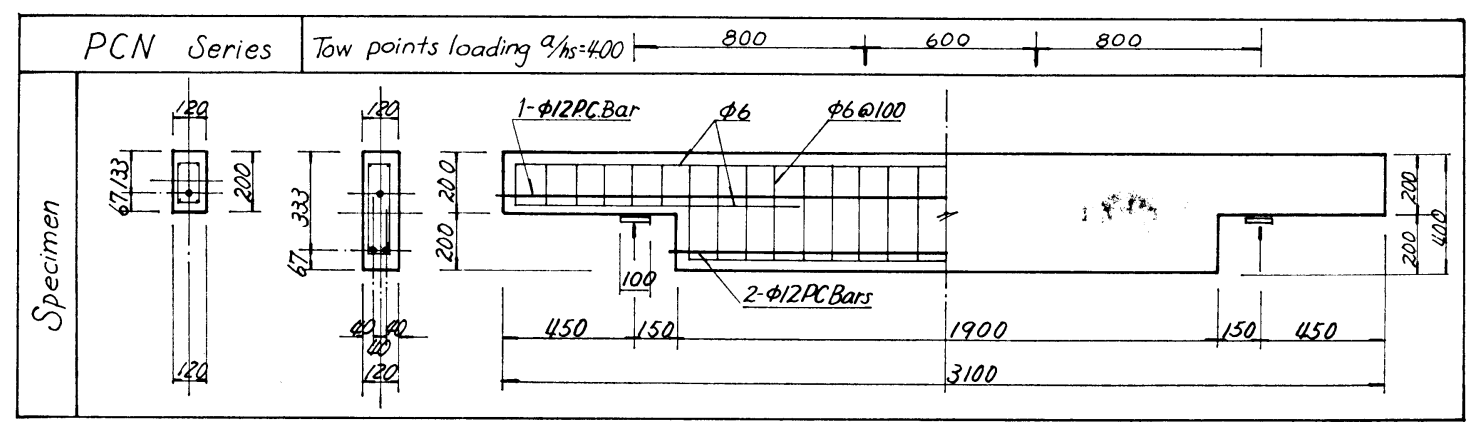

Fig. 3 (a) Specimens and loading arrangement of prestressed concrete rectangular beams 


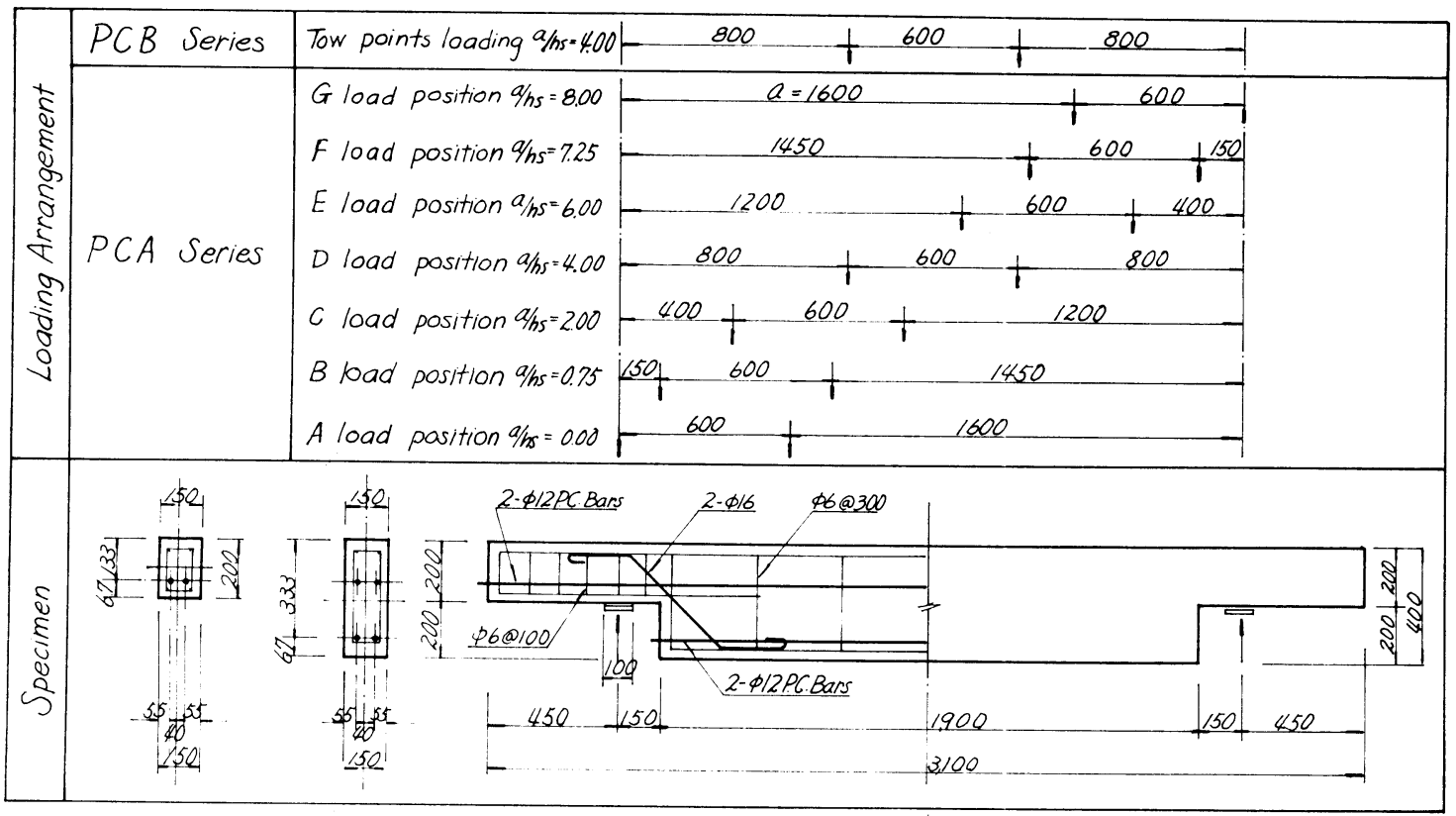

Fig. 3 (b) Specimens and loading arrangement of prestressed concrete rectangular beams

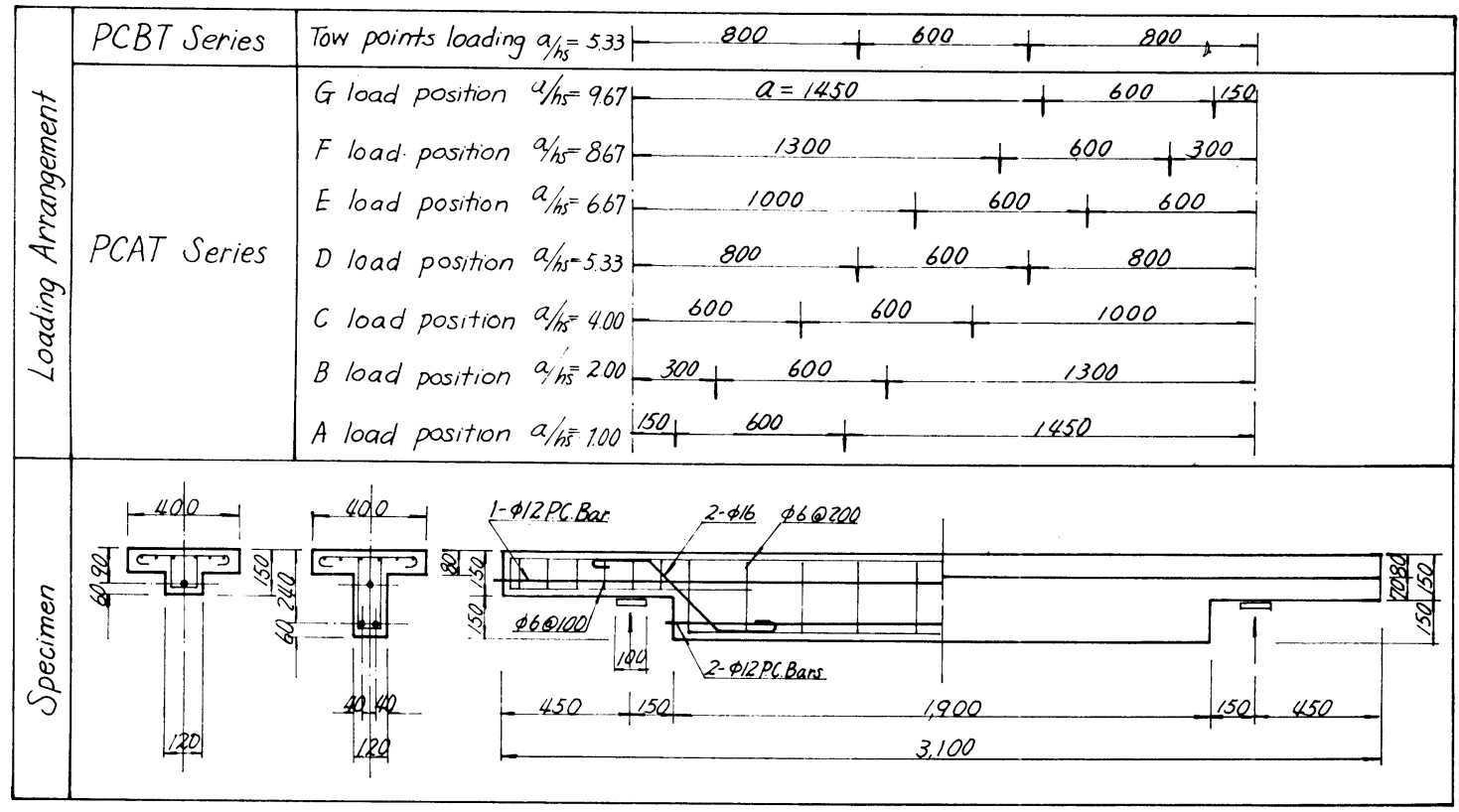

Fig. 4 Specimens and loading arrangement of prestressed concrete tee beams

Table 1 Calculated and experimental analysis of results (Reinforced concrete beams)

\begin{tabular}{|c|c|c|c|c|c|c|c|c|c|c|c|c|c|c|}
\hline \multirow{2}{*}{ Specimens } & \multicolumn{9}{|c|}{ Experimental } & \multicolumn{4}{|c|}{ Calculated } & \multirow{2}{*}{$\frac{\text { Calculated }}{\text { Experimental }}$} \\
\hline & $\begin{array}{l}h_{s} \\
\mathrm{~cm}\end{array}$ & $\begin{array}{l}d_{s} \\
\mathrm{~cm}\end{array}$ & $\begin{array}{l}b_{0} \\
\mathrm{~cm}\end{array}$ & $\begin{array}{c}b \\
\mathrm{~cm}\end{array}$ & $\begin{array}{l}A_{S H} \\
\mathrm{~cm}^{2}\end{array}$ & $\begin{array}{l}A_{S D} \\
\mathrm{~cm}^{2}\end{array}$ & $\begin{array}{c}\sigma_{t u} \\
\mathrm{ky} / \mathrm{cm}^{2}\end{array}$ & $a / h_{s}$ & $\begin{array}{l}M_{c} \\
\mathrm{t}-\mathrm{m}\end{array}$ & $\begin{array}{c}x \\
\mathrm{~cm}\end{array}$ & $\alpha_{c}$ & $\begin{array}{c}Z \\
\mathrm{~cm}^{3}\end{array}$ & $\begin{array}{l}M_{c} \\
\mathrm{t}-\mathrm{m}\end{array}$ & \\
\hline $\mathrm{RCN}$ & 20 & 17 & & 12 & 4.02 & 4.02 & 28.5 & 3.00 & 0.225 & 11.17 & 0.51 & 1128 & 0.164 & 0.73 \\
\hline $\mathrm{RCA}$ & 20 & 17 & - & 12 & 4.02 & 4.02 & 37.7 & 0.75 & 0.225 & 11.68 & 0.51 & 1096 & 0.210 & 0.94 \\
\hline RCBT & 15 & 12 & 12 & 40 & 4.02 & 4.02 & 33.6 & 4.00 & 0.190 & 6.17 & 0.51 & 825 & 0.143 & 0.75 \\
\hline RCAT & 15 & 12 & 12 & 40 & 4.02 & 4.02 & 37.2 & 2.00 & 0.200 & 6.14 & 0.51 & 837 & 0.157 & 0.79 \\
\hline
\end{tabular}


Table 2 Experimental and calculated analysis of results (Prestressed concrete beams)

\begin{tabular}{|c|c|c|c|c|c|c|c|c|c|c|c|c|c|c|}
\hline \multirow[b]{2}{*}{ Specimens } & \multicolumn{9}{|c|}{ Experimental } & \multicolumn{4}{|c|}{ Calculated } & \multirow[b]{2}{*}{$\frac{\text { Calculated }}{\text { Experimental }}$} \\
\hline & $\begin{array}{l}h_{s} \\
\mathrm{~cm}\end{array}$ & $\begin{array}{l}d_{s} \\
\mathrm{~cm}\end{array}$ & $\begin{array}{l}b_{0} \\
\mathrm{~cm}\end{array}$ & $\begin{array}{c}b \\
\mathrm{~cm}\end{array}$ & $\begin{array}{c}A_{S H} \\
\mathrm{~cm}^{2}\end{array}$ & $\begin{array}{c}A_{S D} \\
\mathrm{~cm}^{2}\end{array}$ & $\begin{array}{c}\sigma_{t u} \\
\mathrm{ky} / \mathrm{cm}^{2}\end{array}$ & $a / h_{s}$ & $\begin{array}{l}M_{c} \\
\text { t-m }\end{array}$ & $\begin{array}{c}x \\
\mathrm{~cm}\end{array}$ & $\alpha_{c}$ & $\begin{array}{c}Z \\
\mathrm{~cm}^{3}\end{array}$ & $\begin{array}{l}M_{c} \\
\mathrm{t}-\mathrm{m}\end{array}$ & \\
\hline $\mathrm{PCN}$ & 20 & 13.3 & -.. & 12 & 0.97 & - & 29.0 & 4.00 & 0.355 & 10.00 & 0.87 & 800 & 0.247 & 0.70 \\
\hline PCA & 20 & 13.3 & $\ldots$ & 15 & 1.93 & 4.02 & 35.3 & 0.75 & 0.418 & 9.28 & 0.87 & 957 & 0.363 & 0.87 \\
\hline $\mathrm{PCB}$ & 20 & 13.3 & $\ldots$ & 15 & 1.93 & 4.02 & 34.0 & 4.00 & 0.450 & 9.36 & 0.87 & 960 & 0.352 & 0.78 \\
\hline PCBT & 15 & 9.0 & 12 & 40 & - & 4.02 & 43.6 & 5.33 & 0.263 & 5.72 & 0.87 & 625 & 0.264 & 1.00 \\
\hline PCAT & 15 & 9.0 & 12 & 40 & - & 4.02 & 35.6 & 2.00 & 0.245 & 5.77 & 0.87 & 665 & 0.236 & 0.96 \\
\hline
\end{tabular}

tested by the moving load, VIZ., the load was applied from $A$ load position to $G$ load position at each increment of loading unitil failure occarred to examine the effect of shear span depth ratio on the corner cracking. The details of these specimens are given in Fig. 1, 2, 3, 4 and Table 1, 2.

\section{DEFINITION OF INITIAL CORNER CRACKING MOMENTS}

Before the disscusion of initial corner cracking moments, we should decide the definition of cracking moments. From the standpoint of mantinance or durability of the structure, the cracking moment should be defined as the moment when the crack of the structure reaches to the limit of the allowable width. But there are many difficulties to determine the width of cracks accurately. Irregularity of crack width, location of measurement, and kind of apparatus for measurement will be the problems at the time measurement.

In this paper, for experimental purpose, the corner cracking moment is defined as the moment at which the first corner crack discovered by the naked eyes and which is acting on the cross section cutting the corner. For theoritical purpose, the initial corner cracking moment is defined as the moment at which the principal tensile stress at the reentrent corner of brackt reaches the value of the limiting stress, $\sigma_{t u}$.

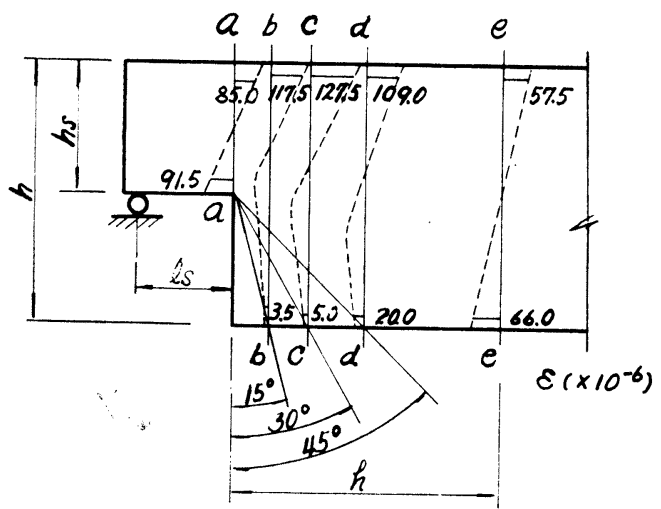

Fig. 5 Typical strain distribution by the load

\section{INITIAL CORNER CRACKING MOMENT OF REINFORCED CONCRETE BEAMS}

In Fig. 6 the inclined line $a \sim f$ at an angle $\theta_{i}$ shows the initial corner crack. This corner crack will be formed under any condition of loading if the principal tensile stress, $\sigma_{1}$, at the reentrent corner of bracket " $a$ " reaches the value of the limiting stress $\sigma_{t u}$.

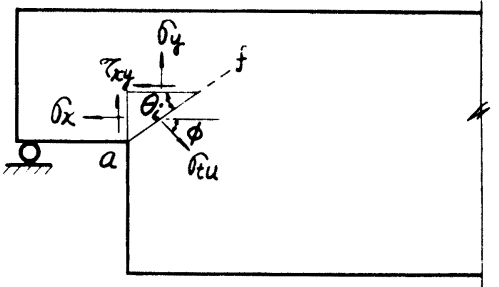

Fig. 6 The stresses just before corner cracking

Let there be given an elementary triangular prism, cut from " $a$ " which there are acting the unit stresses as shown in Fig. 6. When the principal tensile stress, $\sigma_{1}$ reaches $\sigma_{t u}$ the normal stress of this elementary triangular prism become $\sigma_{x}$. Put the relation between $\sigma_{x}$ and $\sigma_{t u}$ as equation (1)

$$
\sigma_{x}=\alpha_{c} \sigma_{t u}
$$

Consider section $a-a$ of Fig. 5 and assume that the stress distribution as Fig. 7. We can calculate

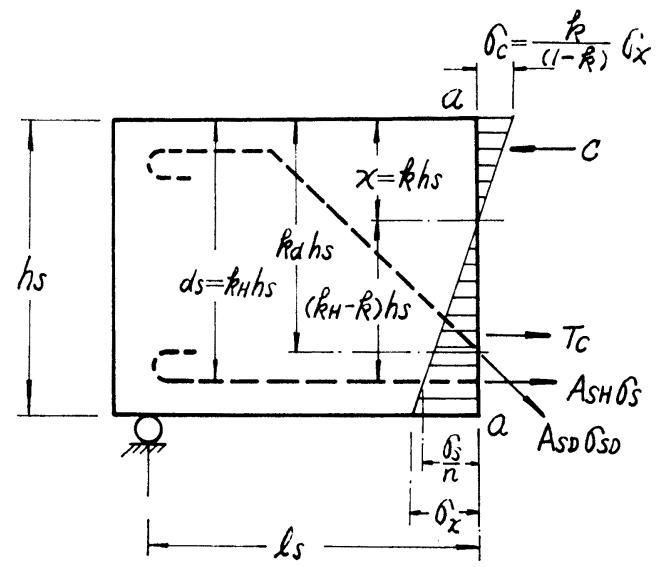

Fig. 7 The stress distribution of bracket base 
the resisting moment, $M$, by the following equation

$$
M=Z \sigma_{x}
$$

Combining Eq. (1) and (2) we obtain;

$$
M_{c}=\alpha_{c} Z \sigma_{t u}
$$

\section{INITIAL CORNER CRACKING MOMENTS OF PRESTRESSED CONCRETE BEAMS}

Fig. 8 shows the elementary triangular prism which is cut from the reentrent corner of bracket of the prestressed concrete beam. The unit stresses acting on the elementary triangular prism are occured only from the prestressing force, the relationship of these stresses being given by

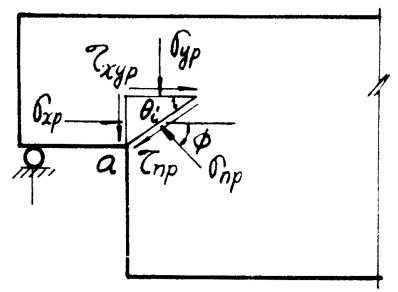

Fig. 8 The stresses due to the prestress

where

$$
\sigma_{n p}=\sigma_{x p} \cos ^{2} \phi+\sigma_{y p} \sin ^{2} \phi+\tau_{x y p} \sin 2 \phi \cdots(4)
$$

$$
\phi=\left(90^{\circ}-\theta_{i}\right)
$$

then we may rewrite as

$$
\sigma_{n p}=\sigma_{x p} \sin ^{2} \theta_{i}+\sigma_{y p} \cos ^{2} \theta_{i}+\tau_{x y p} \sin 2 \theta_{i} \cdots \text { (5) }
$$

now, if the beam is subjected to the load, normal stress, $\sigma_{n p}$, will occur on plane making an angle $\theta_{i}$ with the beam axis and will change its quantity and approach the limiting stress, $\sigma_{t u}$, as shown in Fig. 6. At this stage the initial corner cracking moment will be written as

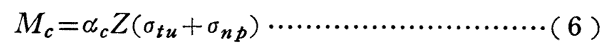

where $\sigma_{t u}, \sigma_{n p}$ represent the absolute value. Substituting equation ( 5 ) in (6), it will be

$$
\begin{aligned}
M_{c}= & \alpha_{c} Z\left(\sigma_{t u}+\sigma_{x p} \sin ^{2} \theta_{i}+\sigma_{y p} \cos ^{2} \theta_{i}\right. \\
& \left.+\tau_{x y p} \sin 2 \theta_{i}\right) \ldots \ldots \ldots \ldots \ldots \ldots \ldots \ldots \ldots \ldots \ldots \ldots \ldots \ldots \ldots \ldots
\end{aligned}
$$

If it can be assumed that

$$
\sigma_{y p}=0
$$$$
\tau_{x y p}=0
$$

then

$$
M_{c}=\alpha_{c} Z\left(\sigma_{t u}+\sigma_{x p} \sin ^{2} \theta_{i}\right)
$$

\section{COEFFICIENT, $\boldsymbol{\alpha}_{c}$}

For evaluation of the coeffecient, $\alpha_{c}$, the following assumptions are made :

(1) The initial inclination angle of the corner crack with respect to the horizontal beam axis is assumed to be known.

(2) At section $a-a$ of Fig. 5, the flow of stresses may be assumed to be not yet irregular and the strain distribution follows the Bernoulli's hypothesis of the linear strain distribution.

(3) The crack will be developed when the principal tensile stress at the reentrent corner reached the tensile strength of the concrete.

Referring to Fig. 6. the following relationship can be obtained

$$
\begin{aligned}
& \sigma_{t u}=\frac{\sigma_{x}+\sigma_{y}}{2}+\sqrt{\left(\frac{\sigma_{x}-\sigma_{y}}{2}\right)^{2}+\tau^{2}{ }_{x y}} \cdots \cdots \cdots \\
& \frac{2 \tau_{x y}}{\sigma_{x}-\sigma_{y}}=\tan 2 \phi
\end{aligned}
$$

where

$$
\tan 2 \phi=\tan 2\left(90-\theta_{i}\right)=-\tan 2 \theta_{i}
$$

and assume

$$
\sigma_{y}=0
$$

then

$$
\tau_{x y}=-\frac{\sigma_{x}}{2} \tan 2 \theta_{i}
$$

from equations (9) and (11), we have

$$
\sigma_{x}=\frac{2}{1+\sqrt{1+\tan ^{2} 2 \theta_{i}}} \sigma_{t u}
$$

compare equations (1) and (12), it can put as follows ;

$$
\begin{aligned}
& \alpha_{c}=\frac{2 \cos 2 \theta_{i}}{\cos 2 \theta_{i}+\cdot 1} \\
& 0<\alpha_{c}<1
\end{aligned}
$$

\section{SECTION MODULUS, $Z$}

\section{(1) Rectangular Section}

In Fig. 7. We assume approximatly

$$
\begin{aligned}
& k_{d} \doteqdot k_{H} \\
& \sigma_{S D} \doteqdot \frac{\sigma_{s}}{\cos \theta_{1}} \quad \theta_{1}<90^{\circ}
\end{aligned}
$$

For equilibrium, $T=C$

$$
\begin{aligned}
C & =\frac{x^{2} b}{2\left(h_{s}-x\right)} \sigma_{x} \ldots \ldots \ldots \ldots \ldots \ldots \\
T_{c} & =\frac{\left(h_{s}-x\right) b \sigma_{x}}{2} \ldots \ldots \ldots \ldots \ldots \ldots \ldots \\
T_{s} & =\frac{n\left(d_{s}-x\right)\left(A_{S H}+A_{S D}\right)}{\left(h_{s}-x\right)} \sigma_{x}
\end{aligned}
$$

equating right hand sides of equations (14), (15) and (16) we have

$$
x=\frac{1}{2} \frac{b h_{s}^{2}+2 n d_{s}\left(A_{S H}+A_{S D}\right)}{b h_{s}+n\left(A_{S H}+A_{S D}\right)}
$$

Taking moments about the neutral axis, the resisting moment at section $a-a$ can be written as

$$
\begin{gathered}
M=\left[\frac{b x^{3}}{3\left(h_{s}-x\right)}+\frac{b\left(h_{s}-x\right)^{2}}{3}\right. \\
\left.+\frac{n\left(A_{S H}+A_{S D}\right)\left(d_{s}-x\right)^{2}}{\left(h_{s}-x\right)}\right] \sigma_{x}
\end{gathered}
$$

the section modulus is given by 


$$
\begin{aligned}
Z= & \frac{b x^{3}}{3\left(h_{s}-x\right)}+\frac{b\left(h_{s}-x\right)^{2}}{3} \\
& +\frac{n\left(A_{S H}+A_{S D}\right)\left(d_{s}-x\right)^{2}}{\left(h_{s}-x\right)} \\
x= & \frac{1}{2} \frac{b h_{s}^{2}+2 n d_{s}\left(A_{S H}+A_{S D}\right)}{b h_{s}+n\left(A_{S H}+A_{S D}\right)}
\end{aligned}
$$

\section{(2) Tee Section}

The section modulus for tee section beams can be obtain by the similar procedure as derivated in the rectangular section, and it can be written as

$$
\left.\begin{array}{rl}
Z= & \frac{b x^{3}+b_{0}\left(h_{s}-x\right)^{3}-\left(b-b_{0}\right)}{3\left(h_{s}-x\right)} \underline{(x-t)^{3}} \\
& +\frac{n\left(A_{S H}+A_{S D}\right)\left(d_{s}-x\right)^{2}}{\left(h_{s}-x\right)} \\
X= & \frac{1}{2} \frac{\left(b-b_{0}\right) t^{2}+b_{0} h_{s}{ }^{2}+2 n d_{s}\left(A_{S H}+A_{S D}\right)}{\left(b-b_{0}\right) t+b_{0} h_{s}+n\left(A_{S H}+A_{S D}\right)}
\end{array}\right\}
$$

For the prestressed concrete beams, the section moduluse of bonded beams should be computed on the basis of the transformed section and the net concrete section is used for unbonded beams (gross concrete section may be conveniently used).

\section{DISCUSSION}

Fig. 9 and 10 show the principal stress at each load stage calculated from the average strain values of eight points on both side of corner of brackets of $\mathrm{RCN}$ and PCN series. These Figures show the principal stress at the corner change both quantity and direction according to the increase of load. In such case, it is more rational to determine the direction of principal stress which is just before the corner cracking according to the inclination angle of the corner crack measured by the crack pattern of tested beams than to determine it by means of

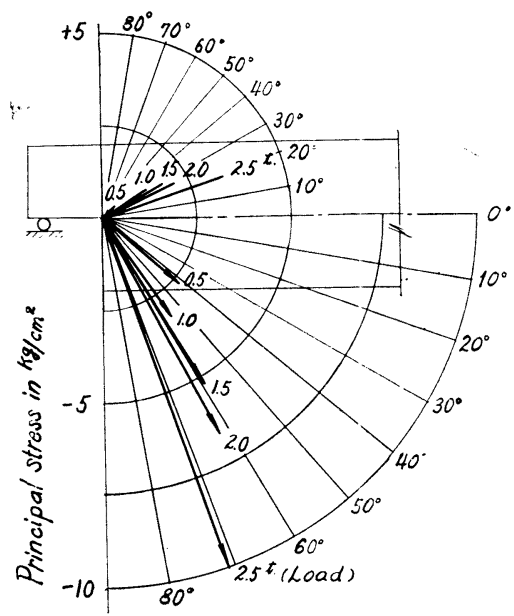

Fig. 9 Principal stress at the corner of bracket of the reinforced concrete specimen

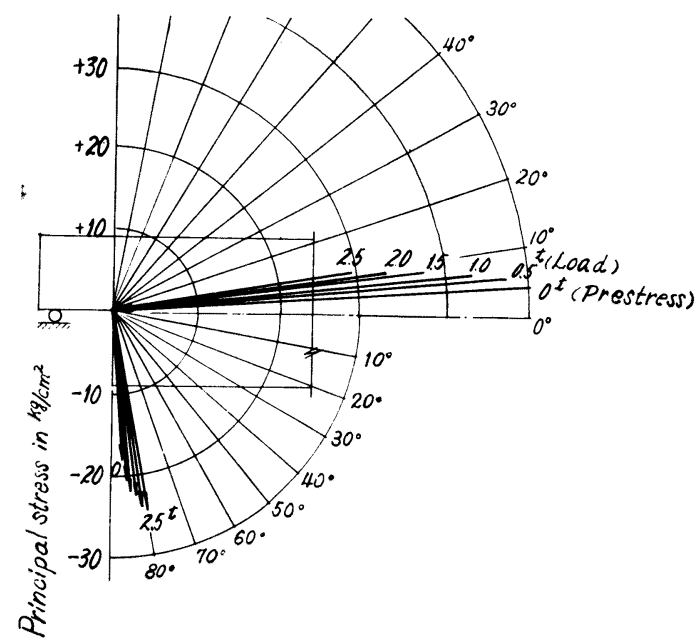

Fig. 10 Principal stress at the corner of bracket of the prestressed concrete specimen

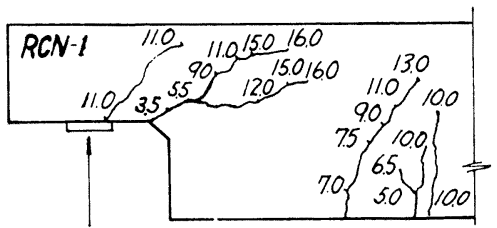

Fig. 11 Crack pattern of reinforced concrete beam

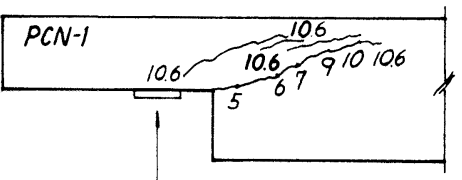

Fig. 12 Crack pattern of prestressed concrete beam

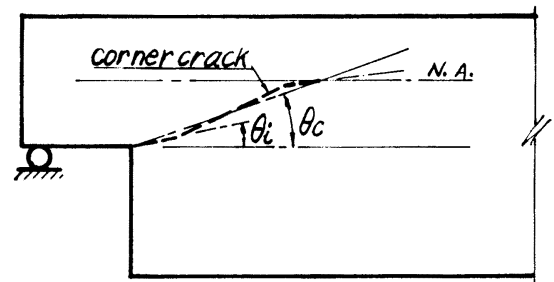

Fig. 13 Idealized pattern of corner crack

calculation from the mesured strain data.

Fig. 11 and 12 show the sketch of crack patterns of the tested specimens. When the stress on the concrete reaches the limiting tensile stress, the corner cracks form diagonally from the reentrent corner of the bracket. After the corner cracks stretch for a short distance and approach reinforcement, they change inclination upward. When the cracks reach a point somewhat above the neutral axis in the compression zone, the corner cracks propagate gradually towards the load point with a flatter slope. An simplified corner crack is shown in Fig. 13. The inclination angle of corner crack, $\theta_{c}$, changes 
Table 3 Inclination angles of corner cracks

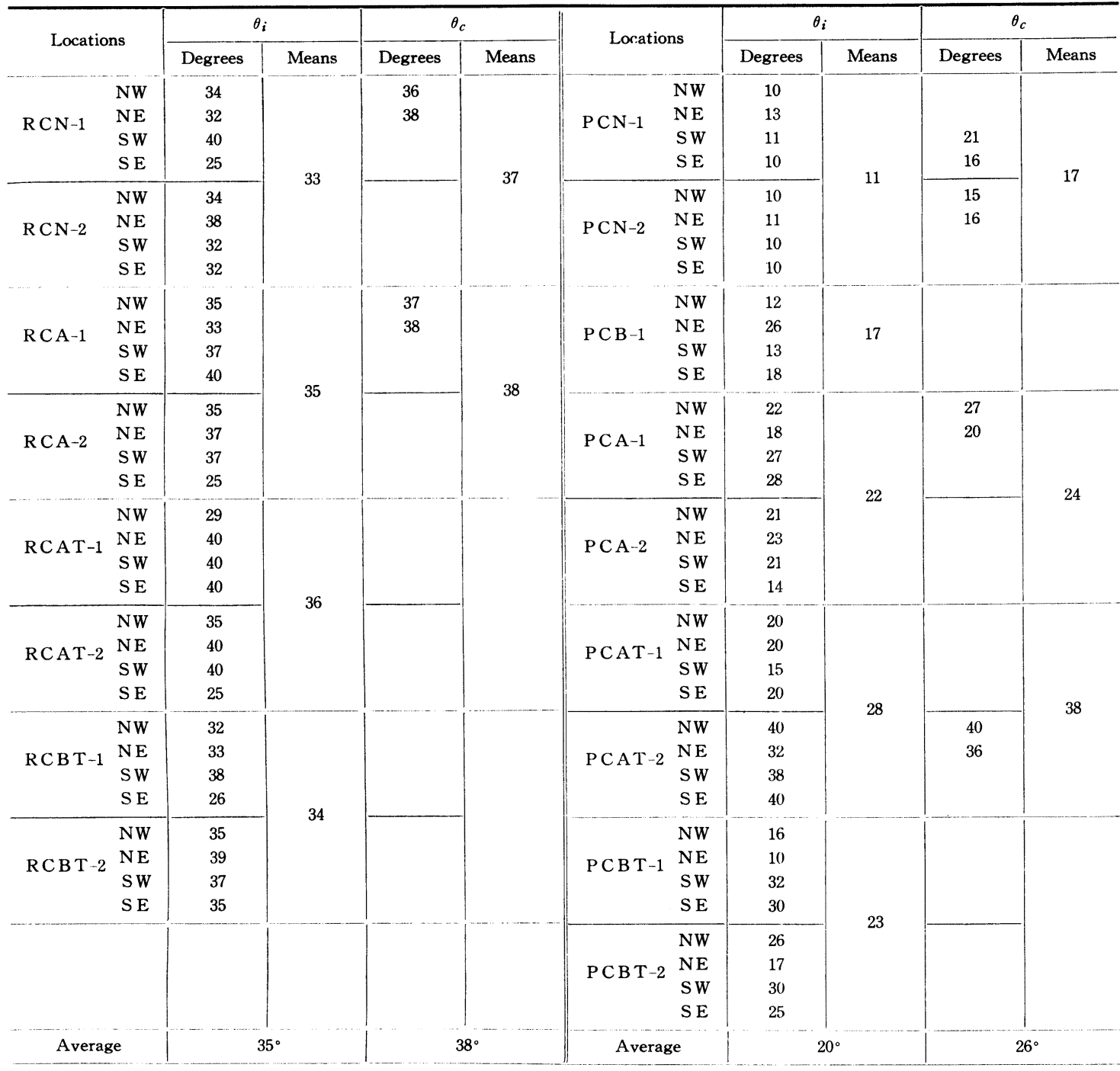

with the prestressing forces and prestressing directions, while the initial inclnation angle $\theta_{i}$ changes approximately between $10^{\circ}$ and $40^{\circ}$ as showed in Table 3 .

It has been found by the tests that the initial inclination angle on the corner cracks has a tendency to inclinate with the beam axis about $35^{\circ}$ in case of reinforced concrete beams and about $20^{\circ}$ in case of prestressed concrete beams.

In the above expression, if $\theta_{i}=35^{\circ}$ is taken for reinforced concrete, it will be;

$$
\begin{aligned}
& \cos 2 \theta_{i}=\cos 70^{\circ}=0.342 \\
& \alpha_{c}=\frac{0.684}{1.342}=0.51
\end{aligned}
$$

and if $\theta_{i}=20^{\circ}$ for prestressed concrete beams $\cos 2 \theta_{i}=\cos 40^{\circ}=0.766$

$$
\alpha_{c}=\frac{1.532}{1.766}=0.87
$$

From another viewpoint, the engineering meaning of reciprocal of $\alpha_{c}$ may be considered as if it were the factor of stress concentration. In other words, the coefficient, $\alpha_{c}$, indicates the degree of irregularities in stress distribution to be given by the abrupt change in depth of cross section.

The test results obtained are given in Tables 1 and 2 together with the results calculated from equations ( 3 ) and ( 8 ) using $\alpha_{c}=0.51$ for reinforced concrete specimens and $\alpha_{c}=0.87$ for prestressed concrete specimens respectively. It is evident from Tables 1 and 2 that the agreement between the experimental corner cracking moments and those calculated by equations (3) and ( 8 ) is generally good. 


\section{DESIGN CHARTS}

The initial corner cracking moment of rectangular beams with brackets is given by the equations (19) and (3) or ( 8 ). It may be rewritten as follows:

$$
\left.\begin{array}{rl}
\frac{M_{c}}{b h_{s}{ }^{2} \alpha_{c} \sigma_{t u}}= & \frac{k^{3}}{3(1-k)}+\frac{(1-k)^{2}}{3} \\
& +\frac{n\left(p_{H}+p_{D}\right)\left(k_{H}-k\right)^{2}}{(1-k)} \\
k=\frac{1}{2} \frac{1+2 n\left(p_{H}+p_{D}\right) k_{H}}{1+n\left(p_{H}+p_{D}\right)}
\end{array}\right\}
$$

the solution of this formula is given in Charts 1 7.

The initial corner cracking moment of tee section beams with brackets is given by the equations (20) and ( 3 ) or ( 8 ) and it may be rewritten as follows:

$$
\left.\begin{array}{rl}
\frac{M_{c}}{b_{0} h_{s}{ }^{2} \alpha_{c} \sigma_{t u}}= & \frac{\left(1-3 k+3 k^{2}\right)}{3(1-k)} \\
& +\frac{\left(\varphi_{1}-1\right)\left(\varphi_{2}{ }^{3}-3 k \varphi_{2}{ }^{2}+3 k^{2} \varphi_{2}\right)}{3(1-k)} \\
& +\frac{n\left(p_{H}+p_{D}\right)\left(k_{H}-k\right)^{2}}{(1-k)} \\
k=\frac{1}{2}\left[\frac{1+2 n\left(p_{H}+p_{D}\right) k_{H}+\left(\varphi_{1}-1\right) \varphi_{2}{ }^{2}}{1+n\left(p_{H}+p_{D}\right)+\left(\varphi_{1}-1\right) \varphi_{2}}\right]
\end{array}\right\}
$$

The solution of his formula is given also in Charts 8 9.

\section{CONCLUSIONS}

(1) The method given in this paper for evaluation of the initial corner cracking moment of reinforced and prestressed concrete beams can be applied with confidence to the design of bracketed parts of the beams of all rectangular, tee sections used in practice.

(2) The initial inclination angles of corner cracks vary between $25^{\circ}$ and $40^{\circ}$ in reinforced concrete beams and between $10^{\circ}$ and $40^{\circ}$ in prestressed concrete beams. For the beams which were ordinary reinforced or prestressed and serve under design load, $\theta_{i}=35^{\circ}$ for reinforced and $\theta_{i}=20^{\circ}$ for prestressed concrete beams are suggested for the computation.

(3) The corner cracking coeffecient $\alpha_{c}=0.51$ for reinforced concrete beams and $\alpha_{c}=0.87$ for prestressed concrete beams are capable of predicting within a reasonable limit.

\section{ACKNOWLEDGMENTS}

The work described in this paper was carried out at the Engineering Materials Laboratory of Waseda University, Tokyo. The author wishes to express his gratitude to Professor Susumu Kamiyama, of the Waseda University, for his valuable comments and helpful advice.

\section{NOTATION}

$a:$ shear span, distance between load point and nearest support

$l:$ span of beam

$l_{s}$ : length of bracket base to the support

$b$ : width of compression face of beam

$b_{0}$ : width of web in tee section

$h$ : over-all depth of beam

$h_{s}$ : over-all depth of bracket

$t:$ thickness of flange in tee section

$d$ : distance from extreme compression fiber to centroid of tension reinforcement of beam

$d_{s}$ : distance from extreme compression fiber to centroid of tension reinforcement of bracket

$M_{c}$ : initial corner cracking moment

$Z$ : section modulus

$n$ : ratio of elasticity of steel to that of concrete

$\sigma_{t u}:$ tensile strength of concrete

$\alpha_{c}:$ coefficient

$\theta_{c}$ : inclination angle of corner crack at shear failure (see Figure 9)

$\theta_{i}$ : initial inclination angle of corner crack

$\theta_{1}$ : angle between inclined steel and longitudinal axis of member

$A_{S H}:$ total area of longitudinal steel

$A_{S V}$ : total area of steel placed perpendicular to the longitudinal reinforcement

$A_{S D}$ : total area of inclined steel

$p_{H}: A_{S H} / b h_{s}$

$p_{V}: A_{S V} / b h_{s}$

$p_{D}: A_{S D} / b h_{s}$

$k_{H}: d_{s} / h_{s}$

$\varphi_{1}: b / b_{0}$

$\varphi_{2}: t / h_{s}$

\section{REFERECES}

1) Kamiyama, S., Chen, W.H., and the others : "The fundamental study of the stress distribution of the bracketed parts of concrete beams", Paper No. 3, the 4 th annual meeting of Japan Prestressed Concrete Engineering Association, Feb. 1964.

2) Kamiyama, S., and Chen, W.H. : "The strength of prestressed concrete beams with brackets', Paper No. 38 , Section IV, the 21 th annual meeting of J.S.C.E., May 1966.

3) Kamiyama, S., and Chen, W.H. : "Moving load tests of prestressed concrete beams with brackets", Paper No. 62, Section IV, the 22th annul meeting of J.S.C. E., May 1967.

4) Kamiyama, S., and Chen, W.H. : "Model analysis of Ultimale shear strength in concrete beams with brackets", Paper No. 37, Section IV, the 23 th annual meeting of J.S.C.E., Oct. 1968.

5) Kamiyama, S., and Chen, W.H. : "A study on the cracking and ultimate strength of the bracket portion 
of reinforced and prestressed concrete beams", Bulletin No. 33, Waseda University, Science and Engineering Research Laboratory, March 1967.

9) Kamiyama, S., and Chen, W.H. : "The Diagonal cracking strength of the bracketed parts of reinforced concrete beams", Paper No. 36, Section IV, the 24 th annual meeting of J.S.C.E., Sept. 1969.

7) Kamiyama, S. : "The reinforcement and shearing stress of the bracketed parts of Prestressed concrete beams." Vol. 7, No. 4, Prestressed Concrete, Aug. 1965 and Vol. 6, No. 4, Prestressed Concrete, Aug. 1964.

8) Okamoto, S., and Ishiwata, T. : "An experience of stress distribution of the supports of suspention beams of gerber girders", Vol. 7, No. 7, Civil Engineering, July 1952.

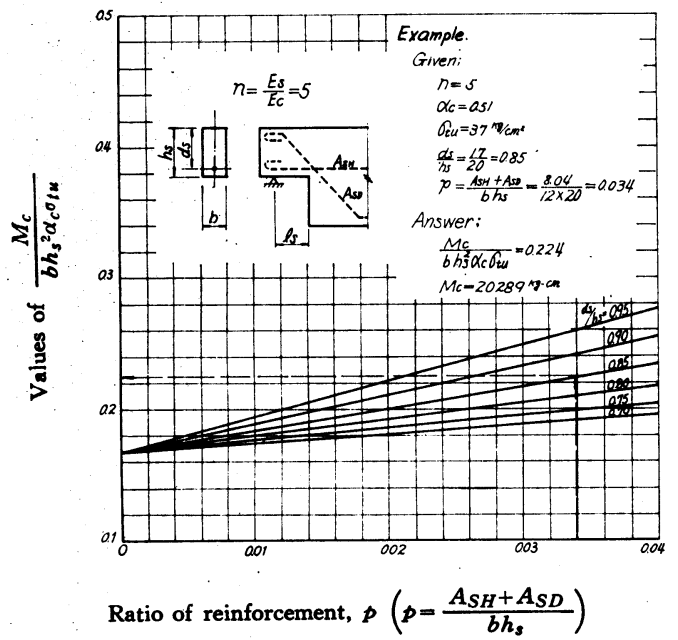

Chart 1 Initial corner cracking moment for rectangular beams $(n=5)$
9) Yokomichi H. : "Design of gerber hings of reinforced concrete girders", Vol. 7, No. 7, Civil Engineering, July 1952 .

10) Onishi, S., Manabe, M., and Hisamatsu, M. : “A structural study on hings of gerber girders by the prestressed concrete," Vol. 8, No. 2, Journal of Japan Prestressed Concrete Engineering Association, April 1966.

11) Fugii, M. : "The method of reinforcement and the equation for predicting the cracking load of the prestressed concrete gerber hings", Paper 42, Section IV, the 24th annual meeting of J.S.C.E., Sept, 1969.

12) Nojiri, Y. and Akiyama, H. : "Stresses of gerber hings by the photoelastic experience", Vol. 7, No.7, Journal of Japan National Council on Concrete, July 1969.

(Received Aug. 24, 1970)

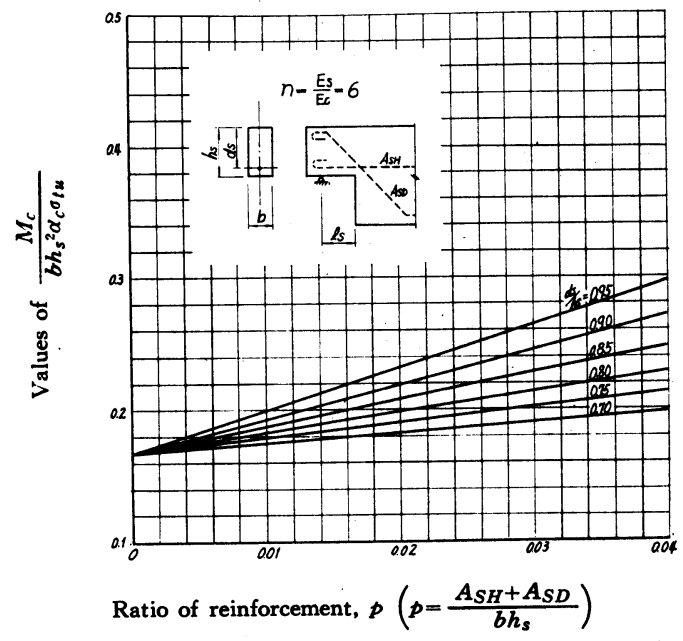

Chart 2 Initial corner cracking moment for rectangular beams $(n=6)$

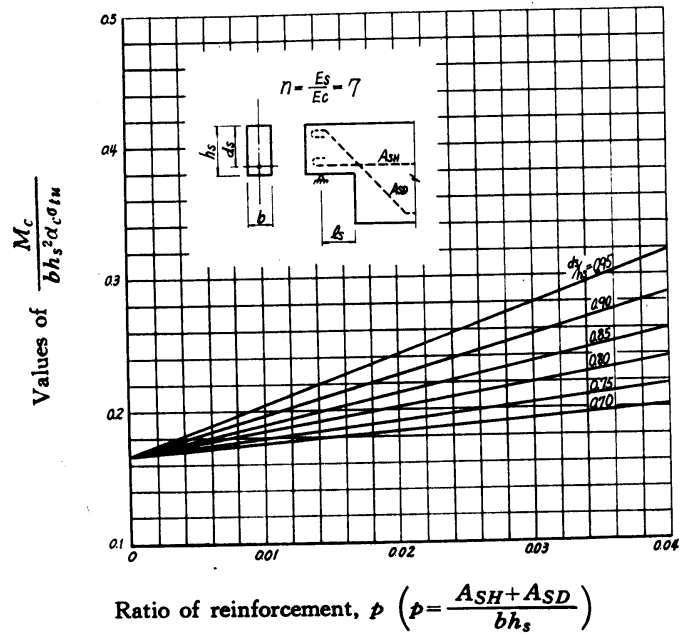

Chart 3 Initial corner cracking moment for rectangular beams $(n=7)$ 


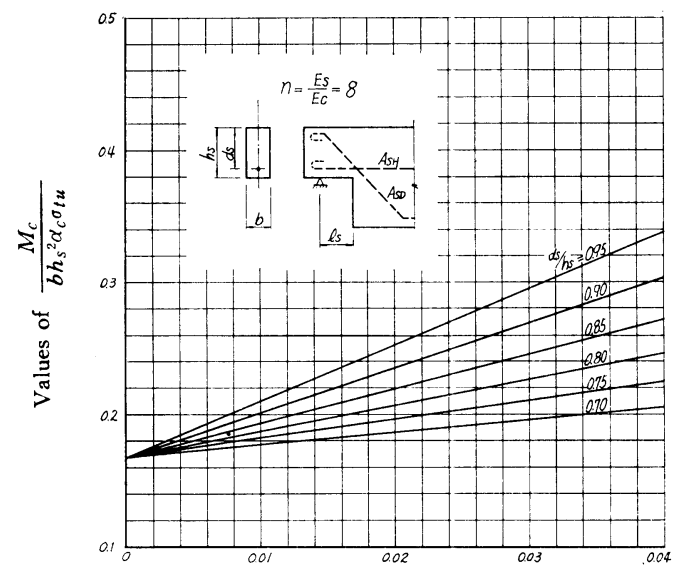

Ratio of reinforcement, $p\left(p=\frac{A_{S H}+A_{S D}}{b h_{S}}\right)$

Chart 4 Initial corner cracking moment for rectangular beams $(n=8)$

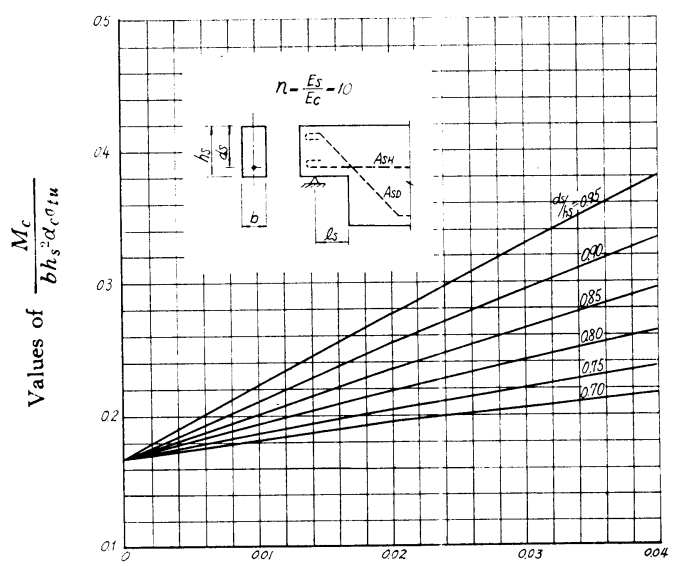

Ratio of reinforcement, $p\left(p=\frac{A_{S H}+A_{S D}}{b h_{s}}\right)$

Chart 6 Initial corner cracking moment for rectangular beams $(n=10)$

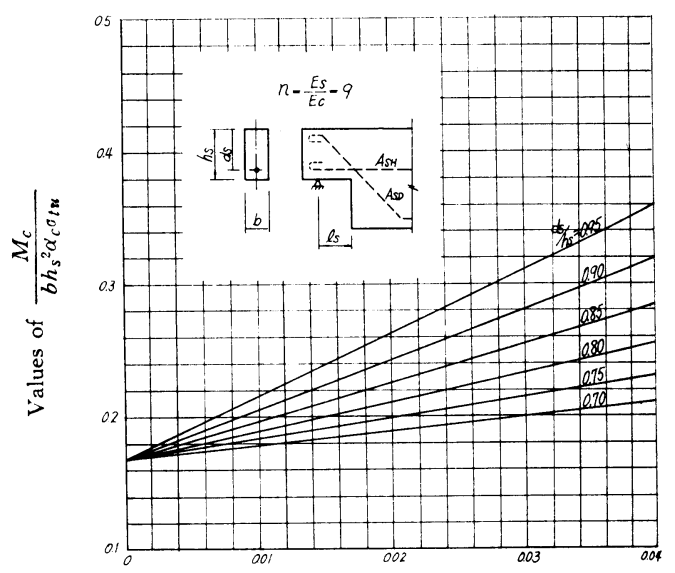

Ratio of reinforcement, $p\left(p=\frac{A_{S H}+A_{S D}}{b h_{S}}\right)$

Chart 5 Initial corner cracking moment for rectangular beams $(n=9)$

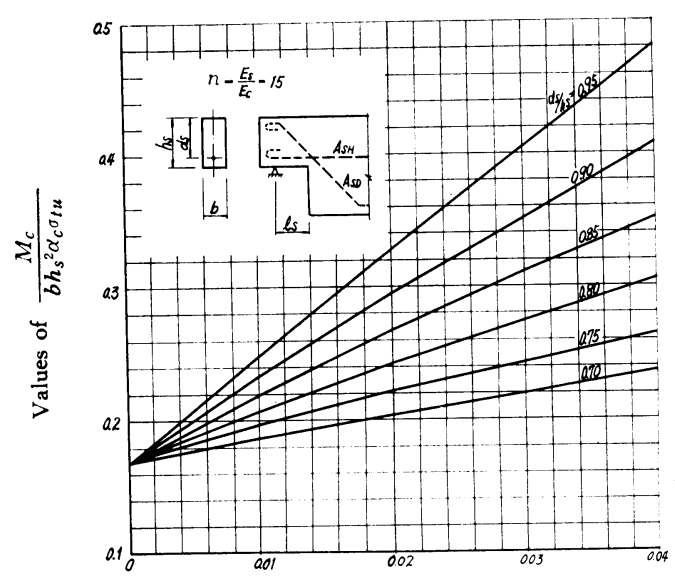

Ratio of reinforcement, $p\left(p=\frac{A_{S H}+A_{S D}}{b h_{S}}\right)$

Chart 7 lnitial corner cracking moment for rectangular beams $(n=15)$ 


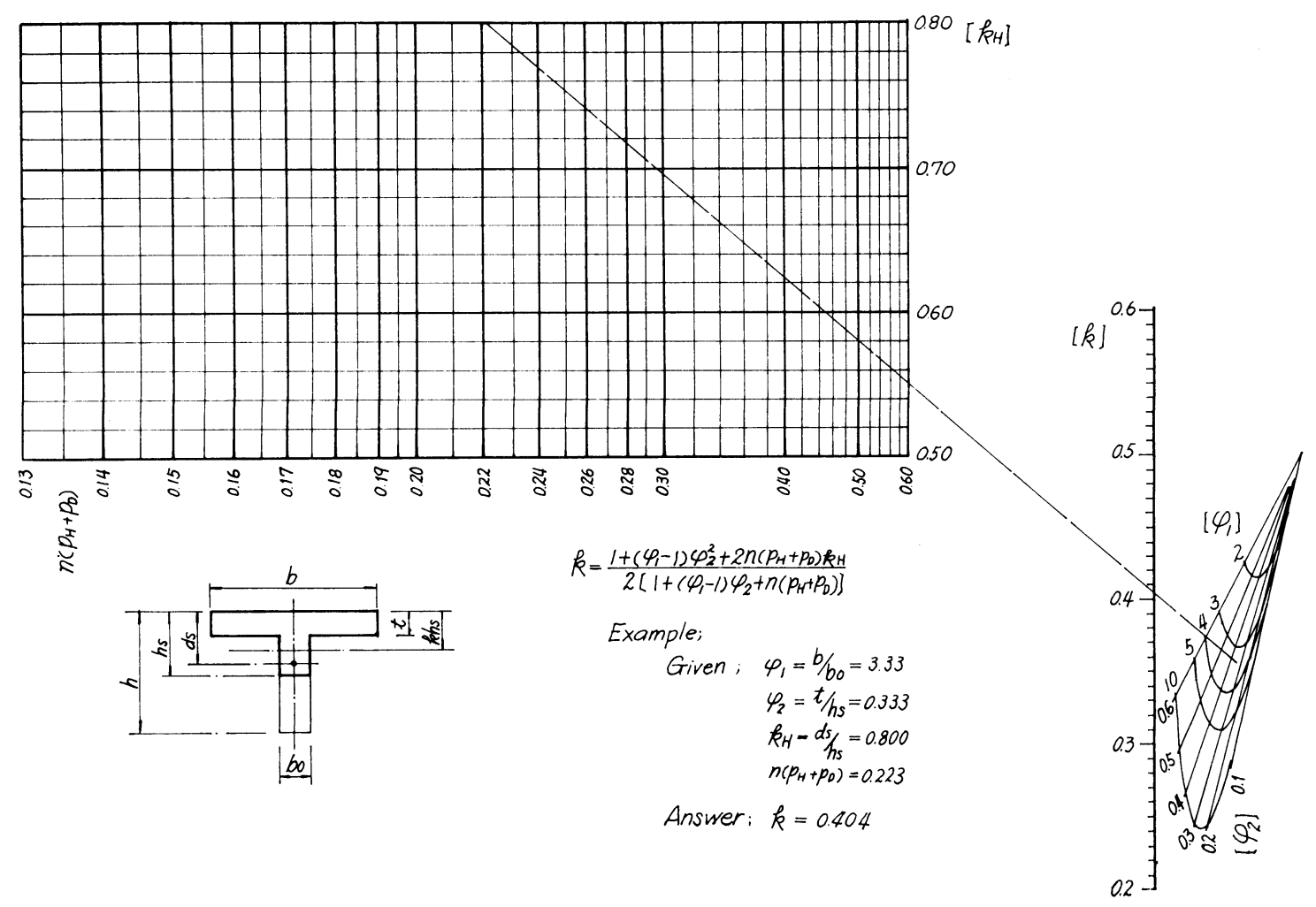

Chart 8 Nomograhy for location of neutral axis

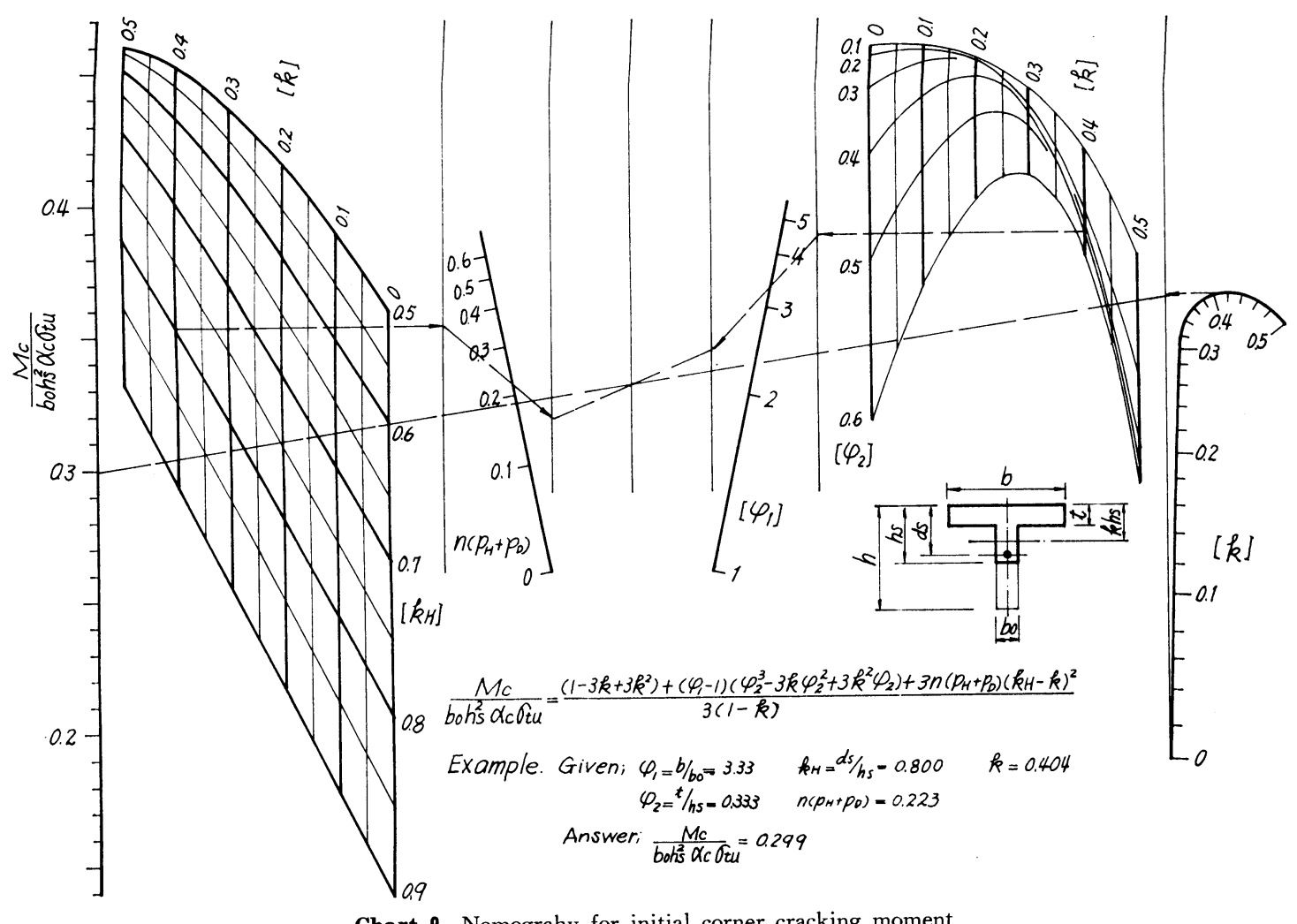

Chart 9 Nomograhy for initial corner cracking moment 